\title{
Women Veterans and Intimate Partner Violence: Current State of Knowledge and Future Directions
}

\author{
Megan R. Gerber, MD, MPH, ${ }^{1,2}$ Katherine M. Iverson, $\mathrm{PhD}^{3,4}$ Melissa E. Dichter, PhD, MSW, \\ Ruth Klap, PhD, ${ }^{6}$ and Rachel E. Latta, $\mathrm{PhD}^{7}$
}

\begin{abstract}
Intimate partner violence (IPV) is a serious public health concern for all; however, women who experience IPV are more likely to sustain injury and report adverse health consequences. An expanding body of research suggests that experience of IPV is common in women veterans (WV), particularly those who access Veterans Health Administration (VA) services. With unprecedented numbers of women serving in the military and subsequently becoming veterans, it is critical that clinicians and advocates caring for WV understand the impact of IPV on this population. WV have unique risk factors for experiencing IPV, including high rates of premilitary trauma, as well as military sexual trauma and posttraumatic stress disorder (PTSD). Correlates of IPV, traumatic brain injury (TBI) and homelessness, are common among this group. Although research on WV health and IPV is emergent, evidence suggests that IPV results in multiple health sequelae and increased healthcare utilization.

In this context, we next discuss clinical and policy implications for VA. A number of targeted interventions and treatments are available for WV who experience IPV, including evidence-based mental health services. VA is well situated to implement screening programs for WV to facilitate referral to needed services and treatments available both within and outside its facilities. As the population of WV expands, future research will be needed to determine best practices; many avenues of inquiry exist. Finally, WV are strong and resilient; it is crucial that those who work with them recognize evidence of IPV and refer to needed services and evidence-based treatment to enable strength-based recovery.
\end{abstract}

\section{Introduction}

Thtimate Partner Violence (IPV) is a serious public health challenge and a cause of women's poor health worldwide. ${ }^{1-3}$ The Centers for Disease Control and Prevention defines IPV as physical, sexual, or psychological harm or stalking behavior by a current or former partner that occurs on a continuum of frequency and severity. ${ }^{4}$ IPV can occur in heterosexual or same-sex relationships and does not require sexual intimacy or cohabitation. ${ }^{4}$ Approximately $29 \%$ of women and $10 \%$ of men in the United States have experienced rape, physical violence, and/or stalking by an intimate partner and reported at least one measured impact related to these or other forms of violence in that relationship. ${ }^{5}$ In the general population, the highest percentage of women report a first experience with IPV between the ages of 18 and $24 .^{5}$ Further underscoring the effect of young age, the US Department of Justice reported that the highest rates of IPV occur in younger women ages 18-24 and 25-34. ${ }^{6}$ Although we know less about IPV in same-sex relationships, those who identify as lesbian, gay, bisexual or transgender (LGBT) may have increased rates of lifetime IPV (from a same- or opposite-sex partner). ${ }^{7,8}$

Gender has a complex impact on IPV risk; although both women and men experience violence from intimate partners, ${ }^{5}$ women appear more likely than men to experience injuries

\footnotetext{
${ }^{1}$ Women Veterans Health Program, VA Boston Healthcare System, Boston, Massachusetts.

${ }^{2}$ Department of Medicine, Boston University School of Medicine, Boston, Massachusetts.

${ }^{3}$ National Center for PTSD, VA Boston Healthcare System, Boston, Massachusetts.

${ }^{4}$ Department of Psychiatry, Boston University School of Medicine, Boston, Massachusetts.

${ }^{5}$ VA Center for Health Equity Research and Promotion (CHERP), Philadelphia VA Medical Center, Philadelphia, Pennsylvania.

${ }^{6}$ VA Greater Los Angeles Healthcare System, VA HSR\&D Center for the Study of Healthcare Innovation, Implementation and Policy (CSHIIP), Los Angeles, California.

${ }^{7}$ New England Mental Illness Research, Education and Clinical Center (MIRECC), Edith Nourse Rogers Memorial Veterans Administration Hospital, Bedford, Massachusetts.
} 
and fear for their safety as a result of IPV. ${ }^{5}$ Other data suggest that women experiencing IPV are more likely to report poor mental and physical health than are men. ${ }^{9}$ Although they use aggression in relationships, women may be more likely to do so when experiencing IPV. ${ }^{10}$ Certain subpopulations of women are at greater risk for experiencing IPV and its attendant health consequences. This overview focuses on the risk and impact of experiencing IPV among women veterans (WV), a unique and growing group.

The population of women entering military service and becoming veterans is at an all-time high. ${ }^{11}$ This has created a critical national priority for clinicians and policymakers to better understand the scope and impact of IPV in this population. The finding that women veterans' health is poorer than that of their active duty (AD) military and civilian counterparts ${ }^{12}$ further emphasizes the need for understanding social determinants of health that may underlie this disparity. Although IPV is prevalent in the general population, ${ }^{5}$ research regarding IPV and veterans has been limited to date and often focuses on the use of IPV by male veterans. ${ }^{13}$ In response to concerns from front-line providers, VA has begun to move forward to develop a national, systematic response to IPV; however not all WV access VA care, ${ }^{14}$ making it key that community providers understand the unique characteristics of this important population. Thus, the goals of this article are to (1) provide a summary of the current state of knowledge regarding IPV in the WV population, (2) review prevalent conditions that are known to enhance IPV risk among WV, (3) discuss evidence-based treatments for veterans who have experienced IPV, and (4) identify future priorities for research and clinical programming. To accomplish this, we cite general-population studies when they provide important context for the WV-specific discussion. Similarly, we have included study data on $\mathrm{AD}$ women when these data contribute important background regarding WV experience of IPV: for example, elucidating lifetime exposure or enhanced risk for revictimization.

\section{Women Veterans: A Growing Population}

Currently, women comprise nearly $15 \%$ of AD military forces, an increase from $8 \%$ in $1980 .{ }^{15}$ More than 2.2 million WV live in the United States and Puerto Rico. ${ }^{16}$ In 2013, WV made up $10 \%$ of the total veteran population ${ }^{16}$ and now comprise $6 \%$ of the total VA patient population. ${ }^{11}$ Figure 1 shows the 10-year growth in WV using VA care. In the age groups at highest risk for IPV in the general population, ${ }^{6}$ the proportion of WV in VA care exceeds that of male veterans by more than twofold; $42 \%$ of women compared to $12 \%$ of men are under age 45 in VA care ${ }^{11}$ (Fig. 2). WV need access to gender-specific services, including preventive screenings and maternity care, and have higher utilization of primary and mental health $(\mathrm{MH})$ care than do their male counterparts. ${ }^{11}$ These characteristics place WV in frequent contact with primary care (and $\mathrm{MH}$ ) providers. Newer WV of the current conflicts have taken on new roles and responsibilities and have faced unprecedented challenges related to work and family balance while serving. It is estimated that one-third of WV ages 17-24 have children and that 39\% of WV under 65 have children living at home. ${ }^{15}$ While on duty, newer WV have engaged in a wider range of roles and duties in deployment, resulting in exposure to risks previously exclu-

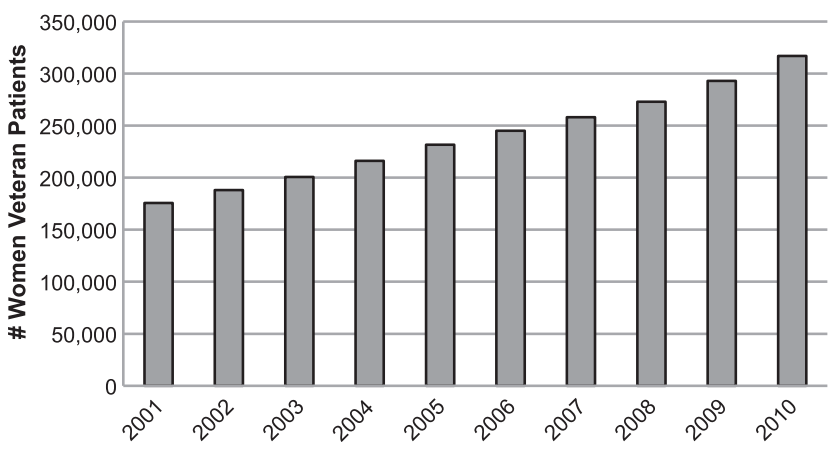

FIG. 1. Number of women VA patients in each fiscal year 2001-2010. Adapted with permission from: Frayne SM, Phibbs CS, Berg E, et al. Sourcebook: Women veterans in the Veterans Health Administration. Volume 2. Sociodemographics and use of VHA and Non-VA care (fee)/ Washington, D.C.: Women's Health Evaluation Initiative, Women's Health Services, Veterans Health Administration, Department of Veterans Affairs; 2012 (October).

sive to men, including combat trauma. ${ }^{17}$ For example, a national study of Operation Enduring Freedom/Operation Iraqi Freedom (OEF/OIF) veterans found that $73 \%$ of women reported one or more combat experiences. ${ }^{18}$ Yet, as a minority in the military, WV report fewer opportunities for peer support while serving. ${ }^{19}$

Since studies in nonveteran women indicate that social support attenuates the negative impact of IPV on health, ${ }^{20}$ we must consider this important contextual variable when addressing the topic of IPV among WV. Although purely speculative, the combination of IPV and lack of social support may contribute to poorer health outcomes for WV. Also pertinent to understanding IPV among veterans is the growing number of dually enlisted military couples: Almost half of military women have married a fellow service member (48\%) compared to $7 \%$ of males. ${ }^{21}$ Elevated rates of PTSD and interpersonal aggression reported among male veterans

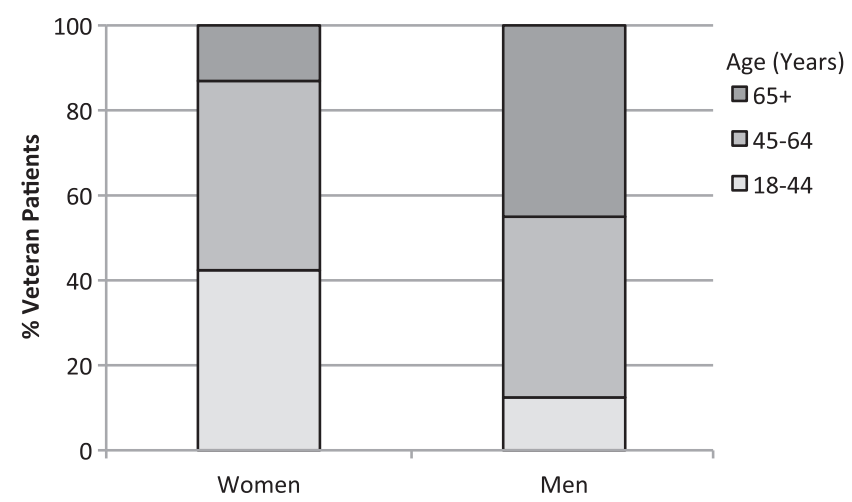

FIG. 2. Age distribution of women and men VA patients, fiscal year 2010. Adapted with permission from: Frayne SM, Phibbs CS, Berg E, et al. Sourcebook: Women veterans in the Veterans Health Administration. Volume 2. Sociodemographics and use of VHA and non-VA care (fee). Washington, D.C.: Women's Health Evaluation Initiative, Women's Health Services, Veterans Health Administration, Department of Veterans Affairs; 2012 (October). 
in the recent conflicts in Iraq and Afghanistan put them at greater risk for using violence in their intimate relationships. ${ }^{22,23}$ Marrying or partnering with male veterans who have PTSD may thus place WV at heightened risk for IPV. ${ }^{13}$

\section{Intimate Partner Violence and WV}

\section{Epidemiology}

A number of studies suggest that both AD service members and veterans are at significant risk for IPV.$^{13,24-26}$ For example, one study of $\mathrm{AD}$ women found that $36 \%$ reported physical, sexual, and/or psychological IPV during service. ${ }^{27}$ Recently, however, the $\mathrm{CDC}$ reported that $\mathrm{AD}$ women and wives of $\mathrm{AD}$ men have lower rates of 12-month and lifetime IPV than do women in the general population. ${ }^{28}$ Yet, other population data demonstrate that WV experience higher rates of lifetime IPV (33.0\% compared to $23.8 \%$ ) than nonveteran women in the same population cohort. ${ }^{29}$ Although the reasons behind this discrepancy have not been established, it is possible that $\mathrm{AD}$ women may experience barriers to reporting that become irrelevant after military service or that WV have postmilitary experiences that increase their exposure to IPV. We must also consider the possibility that the samples of $\mathrm{AD}$ and civilian women were healthier than WV, particularly those accessing VA. ${ }^{12}$

WV using VA services appear to be particularly likely to report IPV. In the Midwest, 74\% of WV primary care patients in a large women's health clinic reported lifetime physical IPV, ${ }^{30}$ and $24 \%$ of female VA patients under the age of 50 reported past-year physical or sexual IPV. ${ }^{31}$ A more recent study in New England found that $29 \%$ of women in recent intimate relationships reported past-year physical, sexual, and/or severe psychological IPV. ${ }^{32}$ In the same sample, the authors evaluated risk factors for past-year IPV ${ }^{33}$ and found that, after adjusting for unwanted sexual experiences during childhood and military service, having less than a college education and service in the Army (vs. other branches) were associated with greater risk for past-year IPV.

\section{Common comorbidities}

Traumatic brain injury. TBI is a physiological disruption in brain function from an external blunt force, such as a blow to the head or strangulation. ${ }^{34}$ TBI can be both a risk factor for $^{35}$ and a sequela of IPV. ${ }^{34}$ Use of physical force by an intimate partner can cause TBI, as abusive partners often use strangulation or blows to a victim's head. ${ }^{34,36}$ In one study, $30 \%$ of IPV survivors reported a loss of consciousness at least once, and $67 \%$ reported residual problems that were potentially related to head injury. ${ }^{37}$ Additionally, individuals with histories of both TBI and IPV manifest neuropsychological deficits, including problems with keeping appointments or completing tasks that require multiple steps. ${ }^{34}$ These executive-function challenges may result in problems accessing and complying with medical care or advocacy services.

TBI is a critical issue for veterans returning from the wars in Iraq/Afghanistan; the overall risk of TBI has increased along with the change in warfare witnessed in those conflicts. ${ }^{38}$ A recent evaluation found that approximately $11 \%$ of female OEF/OIF VA patients screened positive for TBI. ${ }^{39}$ Nonetheless, TBI may go unrecognized, as veterans with TBI often exhibit symptoms suggestive of other MH disorders, such as PTSD, depression, and anxiety. ${ }^{40}$ Preliminary evi- dence indicates that there are gender differences in long-term physical and $\mathrm{MH}$ outcomes among veterans who have experienced a TBI, ${ }^{40}$ underscoring that IPV-related TBI is a key concern in the longitudinal assessment and care of $\mathrm{WV}^{34}$

Homelessness. General-population estimates suggest that $30 \%-90 \%$ of homeless women have experienced IPV. ${ }^{41,42}$ IPV is among the leading contributors to housing instability and homelessness among US women, ${ }^{43}$ who often become homeless as a direct result of fleeing abusive relationships. ${ }^{43,44}$ Women who lack access to stable independent housing are also at increased risk of IPV, as they may be forced to rely on abusive partners for shelter.

These issues present in the general population may be magnified among veterans, who comprise a disproportionate fraction of the nation's homeless population; WV are up to four times more likely to be homeless than nonveteran women. ${ }^{45,46}$ Not surprisingly, IPV is an important contributor to homelessness among WV. ${ }^{47} \mathrm{WV}$ ages $18-29$ are at highest risk of homelessness, ${ }^{48}$ and, as discussed earlier, this age group is rapidly growing in VA. ${ }^{11}$ IPV also leads to and exacerbates $\mathrm{MH}$ conditions, such as PTSD and substance use disorder (SUD), that, in turn, significantly increase the risk for homelessness for WV. ${ }^{45,47}$

\section{Known risk factors and correlates}

Prior interpersonal trauma. Women who experience IPV are known to often have a history of prior interpersonal trauma exposure. ${ }^{4,49,50}$ Frequently, these experiences begin prior to military service, ${ }^{26,51}$ and data suggest that many women join the military in an effort to leave violent and unstable home environments. ${ }^{26}$ For example, a study of Navy recruits found that $30 \%$ of the women reported experience of physical IPV, and $67 \%$ reported psychological IPV prior to enlisting. ${ }^{52}$ In one study of $\mathrm{WV}$, more than half reported premilitary physical or sexual violence; experience of child abuse was also prevalent. ${ }^{26}$

Military sexual trauma. Sexual harassment or assault during military service, referred to within VA as military sexual trauma (MST), is a particularly prevalent and harmful interpersonal trauma experienced by many women who have served in the military. ${ }^{53}$ When perpetrated by an intimate partner, such violence is considered IPV. These experiences of sexual harassment and assault during military service adversely affect subsequent mental and physical health. ${ }^{53-55}$ Rates of IPV are high among WV who report MST. A recent VA study demonstrated that WV with documented IPV exposure were more than 2.5 times likely than women without documented IPV to report MST. ${ }^{56}$ Similarly, in a VA primary care sample, WV who reported current or lifetime IPV were more likely to have experienced MST (Latta, Elwy, Ngo, and Kelly, submitted). Thus, MST appears to be an important risk factor for IPV ${ }^{33,56}$ and likely contributes to cumulative health problems among WV who have been dually exposed to MST and IPV.

Mental health correlates. In the general population, PTSD, ${ }^{57-59}$ depression, ${ }^{60,61}$ and SUD $^{62}$ are important correlates of both use and experience of IPV; women who have experienced IPV exhibit rates of PTSD that range from $31 \%$ to $84 \%$. $^{60}$ Moreover, PTSD symptoms have been shown to increase 
women's risk for subsequent IPV ${ }^{58}$ Depression is also a common risk factor and consequence of IPV,${ }^{60,61}$ with a weighted mean prevalence estimate of $48 \%$ among women who have experienced IPV. ${ }^{60}$

Although comparably fewer studies have been conducted in WV patient populations, ${ }^{2,56,58,63}$ the patterns of association between MH and IPV appear similar to that of the general population. For example, WV who reported past-year IPV experienced significantly higher levels of PTSD and depression symptoms compared to those who had not experienced IPV. ${ }^{32}$ Similarly, SUD is a well-known correlate of IPV among WV, who are at increased risk for misuse of alcohol in comparison to civilian women. ${ }^{56,63}$

\section{Health Impact of IPV for Women Veterans}

Having discussed the epidemiology of IPV in WV along with common psychosocial factors for WV that are linked to and predispose WV to IPV, we now discuss the health impact of IPV on WV. It is well established that IPV adversely impacts women's health in the general population, ${ }^{1,60}$ but there has been a paucity of published research on IPV and WV health. Although our discussion is focused on IPV, it is important to note that experiencing multiple and recurring forms of trauma has a cumulative adverse impact on health. ${ }^{64}$ As noted earlier, WV are a highly trauma-exposed population, ${ }^{51}$ and the health impact of IPV must be considered in this context.

The nascent literature on WV health outcomes reveals that IPV is associated with a myriad of health problems. For example, WV who experienced both sexual and physical assault were more likely to report chronic health conditions and significantly lower health-related quality of life for 10 or more years after military service. ${ }^{65}$ A recent populationbased study found a concerning link between IPV and cardiac risk factors for $\mathrm{WV}$, of great concern because heart disease is the leading cause of death for US women. ${ }^{29,66} \mathrm{WV}$ who have experienced IPV also have higher rates of digestive system disorders than do those who have not experienced IPV. ${ }^{56}$

It appears that the type of IPV a woman veteran experiences may impact the nature of her adverse health outcomes. Psychological IPV is associated with poor self-rated health; physical IPV is associated with chronic pain, smoking, and problem drinking; and sexual IPV is most closely associated with PTSD, other MH diagnoses, and smoking. ${ }^{67}$ Poor health, in turn, drives increased healthcare utilization, and WV who experience IPV have demonstrated increased healthcare use. ${ }^{56}$ In a recent VA study, medical records were examined to determine evidence and quality of IPV-related care; WV who had documentation of IPV in their records had higher average numbers of monthly healthcare encounters, as well as more emergency department visits than did unexposed WV ${ }^{56}$ Fortunately, the same study demonstrated that the majority of WV (95\%) with documented IPV had sought MH or social work treatment. ${ }^{56}$ These data emphasize that because WV are in increased contact with healthcare providers, multiple opportunities exist to identify and treat WV who have experienced IPV. ${ }^{56}$

\section{Clinical and policy implications}

Psychosocial intervention. Although a comprehensive review of IPV-relevant intervention is beyond the scope of this discussion, it is important to acknowledge principles and treatment strategies relevant to addressing IPV among WV. Apart from addressing acute and chronic physical health conditions, IPV-related needs may include-but not be limited to- $\mathrm{MH}$ care, legal advocacy services, employment assistance, and support with child care, housing, and other economic needs. ${ }^{6}$ Program design and care delivery should be driven by the understanding that IPV is an adverse health exposure, not a psychiatric diagnosis. WV should be individually assessed to determine the best course of treatment, which may include a broad array of services: education, advocacy, and supportive services, as well as individual and group treatments for MH correlates of IPV, such as PTSD or SUD. Support and advocacy services focus on safety planning, skill building, provision of information about IPV, and services related to housing, employment, and economic, legal, and parenting needs. ${ }^{69}$

Evidence-based treatment. MH symptoms, such as PTSD and depression, are often chronic in the IPV population and can persist many years after violence has ended. ${ }^{70}$ Fortunately, these sequelae of IPV are treatable with existing evidence-based treatments. Although we are not aware of a WV treatment-outcome study focusing on decreasing psychological distress resulting specifically from IPV, several cognitive-behavioral therapies have been developed for and validated on women who have experienced IPV. Because PTSD is among the most common and severe presentations observed among women who experience IPV ${ }^{60}$ consistent with VA clinical practice guidelines for the management of PTSD, ${ }^{71}$ first-line treatments should focus on trauma. For some women, this type of intervention alone will provide significant symptom relief; others may also benefit from the acquisition of cognitive and emotional skills to further reduce symptoms and possibly help reduce their risk for revictimization.

The wide availability of evidence-based psychotherapies for PTSD within the $\mathrm{VA}^{72}$ is an asset enabling this system to address the MH needs of WV who have experienced IPV. For example, cognitive processing therapy (CPT) is a PTSD treatment that is widely available in VA and has empirical support for the treatment of PTSD and depression among women who have experienced past or recent IPV ${ }^{73}$ Furthermore, evidence suggests that CPT may be able to help reduce women's risk for IPV revictimization by treating their PTSD and depression. ${ }^{74}$ Although not yet disseminated within VA, cognitive trauma therapy for battered women $(\mathrm{CTT}-\mathrm{BW})^{75}$ and Helping to Overcome PTSD through Empowerment $(\mathrm{HOPE})^{76}$ are two evidence-based interventions developed to treat PTSD and its comorbid symptoms among women who have experienced past or recent IPV. It will be important to evaluate these treatments and to develop theoretical models within VA and other healthcare systems that treat WV.

Dialectical behavior therapy (DBT) ${ }^{77}$ and Seeking Safety ${ }^{78}$ are two examples of skills-based interventions that may be effective for WV who have experienced IPV. DBT skills have been effectively adapted for women who experience diverse forms of psychological distress resulting from past and current $\mathrm{IPV}^{79}$ and for WV with chronic trauma-related disorders, including PTSD, subsequent to interpersonal violence. ${ }^{80}$ Seeking Safety, a cognitive-behavioral treatment for 
comorbid PTSD and SUD, has support for effectiveness and feasibility when applied to WV. ${ }^{81}$

\section{VA screening for IPV}

Recently, both the US Preventative Services Task Force and the Institute of Medicine issued recommendations that support the screening and identification of women at risk for IPV. ${ }^{82,83}$ As the sole national integrated health system in the United States, VA is well positioned to implement routine IPV screening and response interventions. ${ }^{84}$ Currently, however, VA has not yet enacted such policy or procedures. ${ }^{84}$ Routine screening for IPV is variable across VA facilities, and many VA primary care providers have had limited training on IPV. ${ }^{85}$ When IPV is disclosed to VA providers, records show minimal documentation, which is sometimes value-laden, and the followup care provided is often unclear from the medical record. ${ }^{86}$ In a VA primary care setting, an IPV screening study of WV who were not using MH services found that $30 \%$ reported current or past experience of IPV (Latta, Elwy, Ngo, Kelly, submitted). Recent work established the clinical utility of the four-item hurt/insult/threaten/ scream (HITS) tool in a sample of female VA patients, ${ }^{32}$ creating a validated and promising means of identifying experience of IPV among WV.

\section{Future Research Directions and Program Development}

As we now have substantial documentation that many WV have experienced IPV, future research can help to identify the particular mechanisms and circumstances that increase $\mathrm{WV}$ risk of IPV. Future work should also evaluate interventions aimed at identifying and addressing IPV and related health needs of WV. Development of evidence-based effective interventions for $\mathrm{WV}$ to both prevent further violence and attenuate the negative impact of violence is important. New research should investigate the intersections between IPV exposure and military experiences. For example, what factors explain the increased rates of IPV for WV, compared with nonveteran women? Are there ways in which particular military service experiences or characteristics are protective for WV who have experienced IPV? Are there particular risks or vulnerabilities associated with military service, or do we need to attend to aspects of the military (e.g., service branch)? Any comprehensive understanding of IPV in WV must also include data on MST; ongoing and future work will further elucidate this connection. We may also need to look more closely at subpopulations of WV to identify characteristics or experiences; examples include LGBT veterans, rural WV, WV of color, or WV with particular physical, cognitive, or emotional characteristics. There may be particular experiences or needs associated with these characteristics that can further guide the development and implementation of interventions aimed at addressing IPV among this at-risk population.

WV use of IPV remains an underexplored area; estimates from males' reports of female-perpetrated IPV do not accurately represent the underlying dynamics of WV use of violence. Given the prevalence of dual-military marriages, ${ }^{21}$ estimates drawn from the male population may yield partial understanding of WV stressors. It is critical, however, that these data not be used to make direct inference about WV use of IPV; future dedicated work in this area is necessary.
As the demographics of the armed services change rapidly, the number of pregnant WV has increased dramatically over the past decade. ${ }^{87,88}$ In non-VA studies, both physical and psychological IPV during pregnancy have been linked to poor outcomes, including low birth weight, preterm delivery, neonatal death, and postpartum depression. ${ }^{89,90}$ IPV may also include coercive interference with contraceptive use. ${ }^{91} \mathrm{AD}$ women have higher rates of unintended pregnancy than the general population, ${ }^{92}$ suggesting that research on the impact of IPV on birth control use is warranted in the WV population. Although rates of IPV during WV pregnancies are not yet known, characteristics of WV, such as higher rates of mental illness ${ }^{88}$ and younger age at first pregnancy, may place them at even higher risk of IPV. Clearly, examination of IPV risk during WV maternity care is an important programmatic priority.

In considering clinical intervention, development of services tailored to WV both in the VA and in the community is essential. Creation of partnerships between VA and military/ community service providers will be critical. In addition to program development and evaluation, research is needed to determine whether existing interventions need to be modified for the WV population. This will include tailoring programs directed at male users of IPV to WV who use IPV; currently, little exists outside of couples interventions to serve these WV.

While we seek to improve services to assist WV who have experienced IPV, focus on primary prevention of new instances of IPV in this population will be of great importance. Such prevention efforts may draw from research that identifies the risks for IPV exposure among this population. In addition to individual risk factors, such work will need to focus on those who use violence, and on military- and VA-led efforts to deter violence, including early intervention and offender accountability. Such efforts will require substantial interprofessional collaboration and will benefit from both quantitative and qualitative research to both identify rates, correlates, and impacts as well as lead to development of a more nuanced understanding of WV's experiences and needs.

\section{Conclusion}

Although this discussion has focused on risk factors for experience of IPV among WV, it is important to emphasize that this group has unique strengths that can aid recovery after IPV. WV have not only persevered as a minority in the armed forces but have also served in unconventional roles with limited social support and role models. ${ }^{93}$ Despite these obstacles, WV develop critical coping processes to manage stress during service, ${ }^{17}$ and the majority of women serving demonstrate strength and resilience in responding to the challenging demands of military life. ${ }^{18}$ Thus, WV exhibit great capacity for recovery but also need access to evidencebased programs and treatment. As numbers of WV continue to grow, it is essential that clinicians, working within and outside of VA, be able to identify risk factors for IPV and provide appropriate referrals and support to WV in need. We have undertaken this summary and discussion of IPV and WV to not only facilitate both identification of IPV and delivery of evidence-based treatment in this deserving population but to also highlight critical knowledge gaps and foster theory-driven work in this area. 


\section{Acknowledgments}

We thank Jason Wright, BS (Women's Health Sciences Division/National Center for PTSD) for his assistance with manuscript preparation.

Funding was provided by VA Health Services Research and Development (HSR\&D) Career Development Award CDA-10-029 (KI); VA HSR\&D Career Development Award CDA-10-202 (MD); and Department of Veterans Affairs, Veterans Health Administration, Office of Research and Development, HSR\&D SDR 10-012 (RK). This work was also supported in part by the Department of Veterans Affairs, Patient Care Services, Women's Health Services (RK). The views expressed in this article are those of the authors and do not necessarily reflect the position or policy of the Department of Veterans Affairs or the US government.

\section{References}

1. Campbell JC. Health consequences of intimate partner violence. Lancet 2002;359:1331-1336.

2. Bonomi AE, Anderson ML, Reid RJ, Rivara FP, Carrell D, Thompson RS. Medical and psychosocial diagnoses in women with a history of intimate partner violence. Arch Intern Med 2009;169:1692-1697.

3. Abramsky T, Watts C, Garcia-Moreno C, et al. What factors are associated with recent intimate partner violence? Findings from the WHO multi-country study on women's health and domestic violence. BMC Public Health 2011;11:109.

4. Centers for Disease Control. Intimate Partner Violence. 2010. Available at: http://www.cdc.gov/violenceprevention/ intimatepartnerviolence/definitions.html Accessed May 24, 2013.

5. Black MC, Basile, KC, Breiding, MJ, et al. National Intimate Partner and Sexual Violence Survey: 2010 Summary Report. Atlanta, GA: National Center for Injury Prevention and Control, Centers for Disease Control and Prevention, 2011.

6. Catalano S. Intimate partner violence, 1993-2010. Available at: http://149.101.16.41/content/pub/pdf/ipv9310.pdf Accessed October 30, 2013.

7. Ard KL, Makadon HJ. Addressing intimate partner violence in lesbian, gay, bisexual, and transgender patients. J Gen Intern Med 2011;26:930-933.

8. Walters ML, Chen J, Breiding, ML. 2010 findings on victimization by sexual orientation. National Intimate Partner and Sexual Violence Survey (NISVS). Available at: http:// www.cdc.gov/violenceprevention/pdf/nisvs_sofindings.pdf Accessed October 20, 2013.

9. Coker AL, Davis KE, Arias I, et al. Physical and mental health effects of intimate partner violence for men and women. Am J Prev Med 2002;23:260-268.

10. Hellmuth JC, Jaquier V, Young-Wolff K, Sullivan TP. Posttraumatic stress disorder symptom clusters, alcohol misuse, and women's use of intimate partner violence. J Trauma Stress 2013;26:451-458.

11. Frayne SM, Phibbs CS, Berg E, et al. Sourcebook: Women veterans in the Veterans Health Administration. Volume 2. Sociodemographics and use of VHA and NonVA Care (fee). 2012. http://www.womenshealth.va.gov/ WOMENSHEALTH/docs/WH_facts_FINAL.pdf. Accessed October 1, 2013.

12. Lehavot K, Hoerster KD, Nelson KM, Jakupcak M, Simpson TL. Health indicators for military, veteran, and civilian women. Am J Prev Med 2012;42:473-480.
13. Marshall AD, Panuzio J, Taft CT. Intimate partner violence among military veterans and active duty servicemen. Clin Psychol Rev 2005;25:862-876.

14. Ouimette P, Wolfe J, Daley J, Gima K. Use of VA health care services by women veterans: Findings from a national sample. Women Health 2003;38:77-91.

15. National Center for Veterans Analysis and Statistics. America's women veterans: Military service history and VA benefits utilization statistics. Washington, D.C.: National Center for Veterans Analysis and Statistics, Department of Veterans Affairs, 2011.

16. Office of the Actuary, Department of Veterans Affairs. VA veteran population projection model, 2011. Available at: http://www.va.gov/vetdata/Veteran_Population.asp Accessed June 6, 2013.

17. Mattocks KM, Haskell SG, Krebs EE, Justice AC, Yano EM, Brandt C. Women at war: Understanding how women veterans cope with combat and military sexual trauma. Soc Sci Med 2012;74:537-545.

18. Street AE, Gradus, JL, Giasson, HL, Vogt, D, Resick, PA. Gender differences among veterans deployed in support of the wars in Afghanistan and Iraq. J Gen Intern Med 2013; 28(Suppl 2):556-562.

19. Vogt DS, Pless AP, King LA, King DW. Deployment stressors, gender, and mental health outcomes among Gulf War I veterans. J Trauma Stress 2005;18:272-284.

20. Coker AL, Watkins KW, Smith PH, Brandt HM. Social support reduces the impact of partner violence on health: Application of structural equation models. Prev Med 2003;37:259-267.

21. Patten E, Parker K. Women in the U.S. military: Growing share, distinctive profile. Available at: http://www.pewsocialtrends.org/files/2011/12/women-in-the-military.pdf Accessed June 7, 2013.

22. Jakupcak M, Conybeare D, Phelps L, et al. Anger, hostility, and aggression among Iraq and Afghanistan war veterans reporting PTSD and subthreshold PTSD. J Trauma Stress 2007;20:945-954.

23. Milliken CS, Auchterlonie JL, Hoge CW. Longitudinal assessment of mental health problems among active and reserve component soldiers returning from the Iraq war. JAMA 2007;298:2141-2148.

24. O'Campo P, Kub J, Woods A, et al. Depression, PTSD, and comorbidity related to intimate partner violence in civilian and military women. Brief Treatment and Crisis Intervention 2006;6:99-110.

25. Teten AL, Schumacher JA, Taft CT, et al. Intimate partner aggression perpetrated and sustained by male Afghanistan, Iraq, and Vietnam veterans with and without posttraumatic stress disorder. J Interpers Violence 2010;25:1612-1630.

26. Sadler AG, Booth BM, Mengeling MA, Doebbeling BN. Life span and repeated violence against women during military service: Effects on health status and outpatient utilization. J Womens Health (Larchmt) 2004;13:799-811.

27. Campbell JC, Garza MA, Gielen AC, et al. Intimate partner violence and abuse among active duty military women. Violence Against Women 2003;9:1072-1092.

28. Black MC, Merrick T. Prevalence of intimate partner violence, sexual violence and stalking among active duty women and wives of active duty men-comparisons with women in the U.S. general population, 2010. Atlanta, GA: National Center for Injury Prevention and Control, 2013.

29. Dichter ME, Cerulli C, Bossarte RM. Intimate partner violence victimization among women veterans and associated 
heart health risks. Womens Health Issues 2011;21(4 Suppl):S190-194.

30. Campbell R, Greeson MR, Bybee D, Raja S. The cooccurrence of childhood sexual abuse, adult sexual assault, intimate partner violence, and sexual harassment: A mediational model of posttraumatic stress disorder and physical health outcomes. J Consult Clin Psychol 2008; 76:194-207.

31. Murdoch M, Nichol KL. Women veterans' experiences with domestic violence and with sexual harassment while in the military. Arch Fam Med 1995;4:411-418.

32. Iverson KM, King MW, Resick PA, Gerber MR, Kimerling R, Vogt D. Clinical utility of an intimate partner violence screening tool for female VHA patients. J Gen Intern Med 2013;28:1288-1293.

33. Iverson KM, Mercado R, Carpenter SL, Street AE. Intimate partner violence among women veterans: Previous interpersonal trauma as a risk factor. J Trauma Stress 2013;26: 767-771.

34. Kwako LE, Glass N, Campbell J, Melvin KC, Barr T, Gill JM. Traumatic brain injury in intimate partner violence: A critical review of outcomes and mechanisms. Trauma Violence Abuse 2011;12:115-126.

35. Farrer TJ, Frost RB, Hedges DW. Prevalence of traumatic brain injury in intimate partner violence offenders compared to the general population: A meta-analysis. Trauma Violence Abuse 2012;13:77-82.

36. Tam S., Joyce D, Gerber MR, Tan AKWT. Head and neck injuries in adult victims of intimate-partner violence. J Otolaryngol Head Neck Surg. 2010;39:737-743.

37. Corrigan JD, Wolfe M, Mysiw WJ, Jackson RD, Bogner JA. Early identification of mild traumatic brain injury in female victims of domestic violence. Am J Obstet Gynecol 2003;188(5 Suppl):S71-76.

38. Hoge CW. Re: "Psychiatric diagnoses in historic and contemporary military cohorts: combat deployment and the healthy warrior effect. Am J Epidemiol 2008;168:10951096; author reply, 1096-1098.

39. Hendricks AM, Amara J, Baker E, et al. Screening for mild traumatic brain injury in OEF-OIF deployed US military: An empirical assessment of VHA's experience. Brain Inj 2013;27:125-134.

40. Iverson KM, Pogoda TK, Gradus JL, Street AE. Deploymentrelated traumatic brain injury among Operation Enduring Freedom/Operation Iraqi Freedom Veterans: associations with mental and physical health by gender. J Womens Health (Larchmt) 2013;22:267-275.

41. Vijayaraghavan M, Tochterman A, Hsu E, Johnson K, Marcus S, Caton CL. Health, access to health care, and health care use among homeless women with a history of intimate partner violence. J Community Health 2012;37: 1032-1039.

42. Browne A, Bassuk SS. Intimate violence in the lives of homeless and poor housed women: Prevalence and patterns in an ethnically diverse sample. Am J Orthopsychiatry 1997;67:261-278.

43. Baker CK, Billhardt KA, Warren J, Rollins C, Glass NE. Domestic violence, housing instability, and homelessness: A review of housing policies and program practices for meeting the needs of survivors. Aggression and Violent Behavior 2010;15:430-439.

44. Anderson DG, Rayens MK. Factors influencing homelessness in women. Public Health Nurs 2004;21:12-23.
45. Washington DL, Yano EM, McGuire J, Hines V, Lee M, Gelberg L. Risk factors for homelessness among women veterans. J Health Care Poor Underserved 2010;21:82-91.

46. Gamache G, Rosenheck R, Tessler R. Overrepresentation of women veterans among homeless women. Am J Public Health 2003;93:1132-1136.

47. Hamilton AB, Poza I, Washington DL. "Homelessness and trauma go hand-in-hand": Pathways to homelessness among women veterans. Womens Health Issues 2011;21(4 Suppl):S203-209.

48. Fargo J, Metraux S, Byrne T, et al. Prevalence and risk of homelessness among US veterans. Prev Chronic Dis 2012;9:E45.

49. Bensley L, Van Eenwyk J, Wynkoop Simmons K. Childhood family violence history and women's risk for intimate partner violence and poor health. Am J Prev Med 2003; 25:38-44.

50. Desai S, Arias I, Thompson MP, Basile KC. Childhood victimization and subsequent adult revictimization assessed in a nationally representative sample of women and men. Violence Vict 2002;17:639-653.

51. Zinzow HM, Grubaugh AL, Monnier J, Suffoletta-Maierle S, Frueh BC. Trauma among female veterans: A critical review. Trauma Violence Abuse 2007;8:384-400.

52. Merrill LL, Stander VA, Thomsen CJ, Crouch JL, Milner JS. Premilitary intimate partner violence and attrition from the U.S. Navy. Mil Med 2006;171:1206-1210.

53. Kimerling R, Street AE, Pavao J, et al. Military-related sexual trauma among Veterans Health Administration patients returning from Afghanistan and Iraq. Am J Public Health 2010;100:1409-1412.

54. Skinner KM, Kressin N, Frayne S, et al. The prevalence of military sexual assault among female Veterans' Administration outpatients. J Interpers Violence 2000;15:291-310.

55. Murdoch M, Pryor JB, Polusny MA, Gackstetter GD. Functioning and psychiatric symptoms among military men and women exposed to sexual stressors. Mil Med 2007; 172:718-725.

56. Dichter ME, Marcus SC. Intimate partner violence victimization among women veterans: Health, healthcare service use, and opportunities for intervention. Mil Behav Med 2013;1:107-113.

57. Kirby AC, Beckham JC, Calhoun PS, et al. An examination of general aggression and intimate partner violence in women with posttraumatic stress disorder. Violence Vict 2012;27:777-792.

58. Iverson KM, Litwack SD, Pineles SL, Suvak MK, Vaughn RA, Resick PA. Predictors of intimate partner violence revictimization: The relative impact of distinct PTSD symptoms, dissociation, and coping strategies. J Trauma Stress 2013;26:102-110.

59. Woods SJ. Intimate partner violence and post-traumatic stress disorder symptoms in women: What we know and need to know. J Interpers Violence 2005;20:394-402.

60. Golding JM. Intimate partner violence as a risk factor for mental disorders: A meta-analysis. Journal of Family Violence 1999;14:99-132.

61. Cougle JR, Resnick H, Kilpatrick DG. A prospective examination of PTSD symptoms as risk factors for subsequent exposure to potentially traumatic events among women. J Abnorm Psychol 2009;118:405-411.

62. Gerber MR. Alcohol and intimate partner violence. In: Boyle P, Boffetta P, Lowenfels AB, Zatonski W, Rehm J, 
eds. Alcohol: Science, policy and public health. Oxford, United Kingdom: Oxford University Press, 2013:194-201.

63. Wallace AE, Sheehan EP, Young-Xu Y. Women, alcohol, and the military: Cultural changes and reductions in later alcohol problems among female veterans. J Womens Health (Larchmt) 2009;18:1347-1353.

64. Rees S, Silove D, Chey T, et al. Lifetime prevalence of gender-based violence in women and the relationship with mental disorders and psychosocial function. JAMA 2011; 306:513-521.

65. Sadler AG, Booth BM, Nielson D, Doebbeling BN. Healthrelated consequences of physical and sexual violence: Women in the military. Obstet Gynecol 2000;96:473-480.

66. Kochanek KD, Xu JQ, Murphy SL, Miniño AM, Kung HC. Deaths: Final data for 2009. National Vital Statistics Reports 2011;60.

67. Dichter ME, Marcus SC, Bonomi AE. Associations between psychological, physical, and sexual intimate partner violence and health outcomes among women veteran VA patients. Soc Work Ment Health 2014; [Epub ahead of print]; DOI:10.1080/15332985.2013.870104.

68. Dichter ME, Rhodes, KV. Intimate partner violence survivors' unmet social service needs. Journal of Social Service Research 2011;37:481-489.

69. Allen NE, Larsen S, Trotter JL, Sullivan CM. Exploring the core components of an evidence-based community advocacy program for women with abusive partners. Journal of Community Psychology 2013;41:1-18.

70. Zlotnick C, Johnson DM, Kohn RM. Intimate partner violence and long-term psychosocial functioning in a national sample of American women. J Interpers Violence 2006;21:262-275.

71. VA/DOD clinical practice guideline for the management of post-traumatic stress. 2004; Version 1.0. Available at: http://www.healthquality.va.gov/ptsd/ptsd_full.pdf Accessed October 15, 2013.

72. Karlin BE, Ruzek JI, Chard KM, et al. Dissemination of evidence-based psychological treatments for posttraumatic stress disorder in the Veterans Health Administration. J Trauma Stress 2010;23:663-673.

73. Iverson KM, Resick PA, Suvak MK, Walling S, Taft CT. Intimate partner violence exposure predicts PTSD treatment engagement and outcome in cognitive processing therapy. Behav Ther 2011;42:236-248.

74. Iverson KM, Gradus JL, Resick PA, Suvak MK, Smith KF, Monson CM. Cognitive-behavioral therapy for PTSD and depression symptoms reduces risk for future intimate partner violence among interpersonal trauma survivors. J Consult Clin Psychol 2011;79:193-202.

75. Kubany ES, Hill EE, Owens JA, et al. Cognitive trauma therapy for battered women with PTSD (CTT-BW). J Consult Clin Psychol 2004;72:3-18.

76. Johnson DM, Zlotnick C, Perez S. Cognitive behavioral treatment of PTSD in residents of battered women's shelters: Results of a randomized clinical trial. J Consult Clin Psychol 2011;79:542-551.

77. Linehan MM. Skills training manual for treating borderline personality disorder. New York: Guilford Press, 1993.

78. Najavits LM. Seeking safety: A treatment Manual for PTSD and substance abuse. New York: Guilford Press, 2002.

79. Iverson KM, Shenk C, Fruzzetti AE. Dialectical behavior therapy adapted for women victims of domestic abuse: A pilot study. Professional Psychology: Research and Practice 2009;40:242-248.

80. Spoont MR, Sayer NA, Thuras P, Erbes C, Winston E. Practical psychotherapy: adaptation of dialectical behavior therapy by a VA Medical Center. Psychiatr Serv 2003; 54:627-629.

81. Desai RA, Harpaz-Rotem I, Najavits LM, Rosenheck RA. Impact of the seeking safety program on clinical outcomes among homeless female veterans with psychiatric disorders. Psychiatr Serv 2008;59:996-1003.

82. Nelson HD, Bougatsos C, Blazina I. Screening women for intimate partner violence and elderly and vulnerable adults for abuse: Systematic review to update the 2004 U.S. Preventive Services Task Force recommendation. Ann Intern Med 2012;156:796-808.

83. Institute of Medicine. Clinical preventive services for women: Closing the gaps. Washington, D.C.: The National Academies Press, 2011.

84. Sweeney AC, Weitlauf JC, Manning EA, Sze JA, Waldrop $\mathrm{AE}$, Hasser C. Intimate partner violence: Perspectives on universal screening for women in VHA primary care. Womens Health Issues 2013;23:e73-76.

85. Iverson KM, Wells ST, Wiltsey-Stirman S, Vaughn R, Gerber MR. VHA primary care providers' perspectives on screening female veterans for intimate partner violence: A preliminary assessment. J Fam Viol 2013;28:823-831.

86. Dichter ME, True G, Marcus SC, Gerlock AA, Yano EM. Documentation of intimate partner violence in women veterans' medical records: An in-depth analysis. Mil Behav Med 2013;1:114-120.

87. Yoon J, Scott JY, Phibbs CS, Frayne SM. Trends in rates and attributable costs of conditions among female VA patients, 2000 and 2008. Women's Health Issues 2012;22:e337-e344.

88. Mattocks KM, Skanderson M, Goulet JL, et al. Pregnancy and mental health among women veterans returning from Iraq and Afghanistan. J Womens Health (Larchmt). 2010; 19:2159-2166.

89. Sarkar NN. The impact of intimate partner violence on women's reproductive health and pregnancy outcome. J Obstet Gynaecol 2008;28:266-271.

90. Yost NP, Bloom SL, McIntire DD, Leveno KJ. A prospective observational study of domestic violence during pregnancy. Obstet Gynecol 2005;106:61-65.

91. Miller E, Decker MR, McCauley HL, et al. Pregnancy coercion, intimate partner violence and unintended pregnancy. Contraception 2010;81:316-322.

92. Grindlay K, Grossman D. Unintended pregnancy among active-duty women in the United States military, 2008. Obstet Gynecol 2013;121(2, Part 1):241-246.

93. Murdoch M, Bradley A, Mather SH, Klein RE, Turner CL, Yano EM. Women and war: What physicians should know. J Gen Intern Med 2006;21(3 Suppl):S5-S10.

Address correspondence to:

Megan R. Gerber, $M D, M P H$ VA Boston Healthcare System/Women Veterans Health Program 150 South Huntington Avenue/PC11 Jamaica Plain, MA 01230

E-mail: Megan.gerber@va.gov 